\title{
Rosiglitazone Regulates Anti-Inflammation and Growth Inhibition via PTEN
}

\author{
Chiou-Feng Lin, ${ }^{1}$ Kung-Chia Young, ${ }^{2}$ Chyi-Huey Bai, ${ }^{3}$ Bu-Chin Yu, ${ }^{4}$ \\ Ching-Ting Ma, ${ }^{1,5}$ Yu-Chieh Chien, ${ }^{2,5}$ Chiu-Ling Chiang, ${ }^{5}$ Chao-Sheng Liao, ${ }^{6}$ \\ Hsin-Wen Lai, ${ }^{6}$ and Chiung-Wen Tsao ${ }^{5}$ \\ ${ }^{1}$ Institute of Clinical Medicine, National Cheng Kung University Medical College, Tainan 70101, Taiwan \\ ${ }^{2}$ Department of Medical Laboratory Science and Biotechnology, National Cheng Kung University Medical College, \\ Tainan 70101, Taiwan \\ ${ }^{3}$ School of Public Health, Taipei Medical University, Taipei 11031, Taiwan \\ ${ }^{4}$ Department of Life Sciences, College of Bioscience and Biotechnology, National Cheng Kung University Medical College, \\ Tainan 70101, Taiwan \\ ${ }^{5}$ Department of Nursing, Chung Hwa University of Medical Technology, No. 89, Wen-Hwa 1st Street, Jen-Te Hsiang, \\ Tainan 71703, Taiwan \\ ${ }^{6}$ Department of Gastroenterology, Shin Kong Wu Ho-Su Memorial Hospital, Taipei 11101, Taiwan
}

Correspondence should be addressed to Chiung-Wen Tsao; tcwhmy@ms58.hinet.net

Received 7 June 2013; Revised 18 January 2014; Accepted 1 February 2014; Published 13 March 2014

Academic Editor: Kazim Husain

Copyright (C) 2014 Chiou-Feng Lin et al. This is an open access article distributed under the Creative Commons Attribution License, which permits unrestricted use, distribution, and reproduction in any medium, provided the original work is properly cited.

\begin{abstract}
Peroxisome proliferator-activated receptor gamma $(\operatorname{PPAR} \gamma)$ agonist has anti-inflammatory and anticancer properties. However, the mechanisms by which PPAR $\gamma$ agonist rosiglitazone interferes with inflammation and cancer via phosphatase and tensin homolog-(PTEN)-dependent pathway remain unclear. We found that lower doses $(<25 \mu \mathrm{M})$ of rosiglitazone significantly inhibited lipopolysaccharide-(LPS)-induced nitric oxide (NO) release (via inducible nitric oxide synthase, iNOS), prostaglandin E2 (PGE 2 ) production (via cyclooxygenase-2, COX-2), and activation of Akt in RAW 264.7 murine macrophages. However, rosiglitazone did not inhibit the production of reactive oxygen species (ROS). In PTEN knockdown (shPTEN) cells exposed to LPS, rosiglitazone did not inhibit NO release, $\mathrm{PGE}_{2}$ production, and activation of Akt. These cells had elevated basal levels of iNOS, COX-2, and ROS. However, higher doses $(25-100 \mu \mathrm{M})$ of rosiglitazone, without LPS stimulation, did not block NO release and $\mathrm{PGE}_{2}$ productions, but they inhibited p38 MAPK phosphorylation and blocked ROS generation in shPTEN cells. In addition, rosiglitazone caused G1 arrest and reduced the number of cells in S + G2/M phase, leading to growth inhibition. These results indicate that the antiinflammatory property of rosiglitazone is related to regulation of PTEN independent of inhibition on ROS production. However, rosiglitazone affected the dependence of PTEN-deficient cell growth on ROS.
\end{abstract}

\section{Introduction}

The thiazolidinedione (TZD) family of drugs is widely used for treatment of type 2 diabetes. TZD activates nuclear regulatory protein peroxisome proliferator-activated receptor gamma (PPAR $\gamma)$ that functions as a transcription factor regulating the expression of various genes and also plays a vital role in modulation of cellular differentiation, development, and metabolism. In addition, TZD inhibits tumorigenesis via regulating cell cycle control, tumor cell recognition of extracellular mitogenic signals, and the expression of angiogenic factors [1-4]. On the other hand, activation of endogenous PPAR $\gamma$ pathway inhibits inflammatory diseases, such as rheumatoid arthritis [5], sepsis [6], and pancreatitis [7]. PPAR $\gamma$ ligands (e.g., 15deoxy-12,14-PGJ2) and TZD (e.g., rosiglitazone and troglitazone) have been proposed to exert anti-inflammatory effects because they may inhibit phorbol myristyl acetateinduced secretion of proinflammatory cytokines (such as tumor necrosis factor- $\alpha$ (TNF- $\alpha)$ and interleukin 6 [8-10]) 
by monocytes and block lipopolysaccharide- (LPS-) induced expressions of the inducible nitric oxide synthase (iNOS) and/or cyclooxygenase-2 (COX-2) $[5,11]$. Thus, these agents have a potential application in inflammation treatment [6] and cancer chemoprevention [12].

Phosphatase and tensin homolog deleted on chromosome 10 (PTEN), which encodes a dual-specificity phosphatase, has protein and lipid phosphatase activities that can antagonize PI3K's ability to promote cell proliferation, growth, metabolism, and survival [13]. PTEN was originally identified as a tumor suppressor gene which is frequently mutated or deleted in a variety of human cancers [14]. Persistent PTEN inactivation may provide an etiological link between inflammation and colorectal cancer $[15,16]$. Cellular PTEN is vulnerable to inactivation by chemically reactive lipid mediators of inflammation and redox stress [16]. Besides, reactive oxygen species (ROS) act as a double-edged sword controlling tumor cell development and inflammation through the activations of transcription factors (e.g., nuclear factor$\kappa \mathrm{B})$ and/or the expression of tumor suppressor genes (e.g., PTEN) [17]. However, the precise mechanism underlying this ROS/PTEN pathway needs further investigation.

Activation of PPAR $\gamma$ by rosiglitazone upregulates PTEN expression in inflammatory and tumor-derived cells, including human macrophages, Caco 2 colorectal cancer cells, and MCF7 breast cancer cells [18]. Several studies have shown that the anti-inflammatory actions and protective roles of PPAR $\gamma$ agonists involve the upregulation of PTEN, but many of these data are contradictory [9, 19, 20]. Furthermore, regulation of $\mathrm{PI} 3 \mathrm{~K} / \mathrm{Akt}$ and mitogen-activated protein kinase (MAPK) is also involved in alleviating inflammation and/or tumorigenesis by PPAR $\gamma$ ligands and its agonists [21-26]. Taken together, these studies show that PTEN may participate in PPAR $\gamma$ ligand-mediated signaling against inflammation or tumorigenesis through coregulation with Akt and MAPK. Currently, it's not clear whether rosiglitazone would elicit a functional effect in cells with PTEN deficiency.

Myeloid lineage, such as monocytes/macrophages, is one of main sources that produces inflammatory mediators and promotes tumor development. In the present study, we used the lentiviral transduction system to stably express short hairpin RNAs for targeted PTEN knockdown in RAW 264.7 murine macrophages to assess changes in inflammatory response and cell growth, with or without LPS stimulation. Next, we utilized a PTEN-deficient cell line to evaluate the inhibitory effects of rosiglitazone on the above signaling pathways and examined how the generation of ROS affects inflammation and cell growth.

\section{Materials and Methods}

2.1. Cell Cultures. RAW 264.7 murine macrophages were purchased from Bioresource Collection and Research Centre (Hsinchu, Taiwan). Cells were maintained $\left(5 \% \mathrm{CO}_{2}, 37^{\circ} \mathrm{C}\right)$ in Dulbecco's modified Eagle's medium (DMEM; Life Technologies, Rockville, MD) supplemented with $10 \%$ heat-inactivated fetal bovine serum (FBS; Invitrogen, Life Technologies, Carlsbad, CA) and $100 \mu \mathrm{g} / \mathrm{mL}$ gentamicin.
2.2. Chemical Reagents. Escherichia coli-derived LPS was obtained from Calbiochem (San Diego, CA). Rosiglitazone was purchased from Cayman Chemical Co. (Ann Arbor, MI). GW9662 was purchased from Tocris Bioscience Co. (Ellisville, MO).

2.3. Antibodies. Mouse anti- $\beta$-actin monoclonal antibody was purchased from Chemicon International, Inc. (Temecula, CA). Antibodies against phospho-Akt (Ser473), Akt, phospho-p38 MAPK (Thr180/Tyr182), p38 MAPK, phosphoextracellular signal-regulated kinase 1/2 (ERK1/2) (Thr202/Tyr204), ERK1/2, phospho-SAPK/JNK (Thr183/Tyr185), SAPK/JNK, and iNOS were purchased from Cell Signaling Technology, Inc. (Beverly, MA). Rabbit anti-cyclooxygenase-2 (COX-2) polyclonal antibody was purchased from Thermo Fisher Scientific Anatomical Pathology (Cheshire, WA, UK).

\subsection{Lentiviral-Based RNA Interference Knockdown. PTEN} knockdown in RAW 264.7 cells was performed using lentiviral transduction to stably express short hairpin RNAs (shRNAs) that target PTEN. shRNA constructs were purchased from the National RNAi Core Facility (Institute of Molecular Biology/Genomic Research Center, Academia Sinica, Taiwan). Both PTEN shRNA construct (TRCN0000028992, containing the shRNA target sequence $5^{\prime}$-GCTAGAACTTATCAAACCCTT- $3^{\prime}$ for mouse PTEN) and the luciferase shRNA construct (TRCN0000072247, containing the shRNA target sequence $5^{\prime}$-GAATCGTCGTATGCAGTGAAA- ${ }^{\prime}$ for a negative control) were used to generate recombinant lentiviral particles. The cells were transduced with the viral particles containing PTEN or luciferase shRNAs for $24 \mathrm{~h}$ and then given fresh medium. Cell supernatants were harvested at $36,48,60$, and $72 \mathrm{~h}$ after transduction and then filtered with a $0.45 \mu \mathrm{m}$ low protein-binding filter. The viral particles were further concentrated by centrifugation at $20,000 \times \mathrm{g}$ at $4^{\circ} \mathrm{C}$ for $2.5 \mathrm{~h}$ and then resuspended with fresh medium. Lentiviral particles (shPTEN and shLuc) were introduced to RAW 264.7 cells with appropriate M.O.I. in medium supplemented with $8 \mu \mathrm{g} / \mathrm{mL}$ polybrene. The knockdown of PTEN was confirmed by Western blotting analysis.

2.5. Determination of NO Release. NO production was determined by measuring the production of nitrite in the supernatant with the Griess reagent. Briefly, $100 \mu \mathrm{L}$ culture supernatant was mixed with $100 \mu \mathrm{L}$ Griess reagent $(1 \%$ sulphanilamide, $0.1 \%$ naphthylethylenediamine dihydrochloride, and $2.5 \% \mathrm{H}_{3} \mathrm{PO}_{4}$ ) for $10 \mathrm{~min}$ at room temperature. The concentration of nitrite was determined spectrophotometrically (Spectra MAX 340PC; Molecular Devices Corporation, Sunnyvale, CA) at $540 \mathrm{~nm}$, and the nitrite concentration was calculated using a standard curve of sodium nitrite with ELISA software (Softmax Pro; Molecular Devices).

2.6. Determination of $\mathrm{PGE}_{2}$ Production. $\mathrm{PGE}_{2}$ production was measured by a PGE 2 EIA kit (Cayman Chemical Co., Ann Arbor. MI). The concentration of $\mathrm{PGE}_{2}$ was measured 
spectrophotometrically (Spectra MAX 340PC) at $420 \mathrm{~nm}$, and $\mathrm{PGE}_{2}$ concentration was calculated using a PGE 2 EIA standard curve with Softmax Pro ELISA software.

2.7. Detection of Intracellular ROS Production. Cells were cultured for indicated times, washed twice with DMEM, and exposed to $20 \mu \mathrm{M}$ 5-(and-6)-chloromethyl-2', $7^{\prime}$ dichlorodihydrofluorescein diacetate (CM- ${ }_{2}$ DCFDA) (Invitrogen) for $1 \mathrm{~h}$. After washing with PBS, cells were analyzed by flow cytometry using an excitation wavelength of $488 \mathrm{~nm}$ (FACSCalibur, BD Biosciences, CA).

2.8. Western Blot Analysis. Cells were harvested at the indicated times and lysed with a buffer containing $1 \%$ Triton $\mathrm{X}-100,50 \mathrm{mM}$ Tris (pH 7.5), $10 \mathrm{mM}$ EDTA, $0.02 \% \mathrm{NaN}_{3}$, and a protease inhibitor cocktail (Sigma-Aldrich). Protein lysates $(40 \mu \mathrm{g})$ were separated via $10 \%$ SDS-polyacrylamide gel electrophoresis and transferred to a polyvinylidene difluoride membrane (Millipore, Billerica, MA). Membranes were blocked at $25^{\circ} \mathrm{C}$ for $1 \mathrm{~h}$ in TBS-T (10 mM Tris, pH 7.6, $150 \mathrm{mM}$ $\mathrm{NaCl}$, and $0.05 \%$ Tween 20 ) containing $10 \%$ skimmed milk and then incubated with 1:1000 diluted primary antibodies at $4^{\circ} \mathrm{C}$ overnight. Subsequently, the blots were washed with TBS-T and incubated with 1:5000 diluted horseradish peroxidase-conjugated secondary antibodies at room temperature for $1 \mathrm{~h}$. The protein bands were visualized using an enhanced chemiluminescence kit (PerkinElmer, Boston, MA). For Western blot analysis, $\beta$-actin was used as the internal control. The optical densities (OD) of phosphoprotein/total protein were determined using the VisionWorks LS software (Upland, CA).

2.9. Cell Cycle Analysis by Flow Cytometry. Cells were harvested from culture dishes, washed in phosphate-buffered saline (PBS), suspended in $200 \mu \mathrm{L}$ ice-cold $70 \%$ ethanol, and incubated on ice for at least $1 \mathrm{~h}$. The cells were then washed with PBS, exposed to RNase A (Sigma), and incubated at $37^{\circ} \mathrm{C}$ for $30 \mathrm{~min}$. The cells were subsequently suspended in propidium iodide (Sigma) in PBS, and DNA analysis was performed using flow cytometry (FACSCalibur). The percentages of cells in sub G1, G0/G1, and S plus G2/M phases were determined.

2.10. Cell Proliferation Assay. The rate of cell growth was determined colorimetrically using the 3-2,5-diphenyl tetrazolium bromide (MTT) assay kit (Chemicon International Inc.). Cells $\left(8 \times 10^{3}\right.$ cells per well $)$ were seeded onto 96 -well plates and cultured for 24 and $48 \mathrm{~h}$. After cells were incubated with the MTT at $37^{\circ} \mathrm{C}$ for $4 \mathrm{~h}$, the supernatants were discarded. One hundred microliters of DMSO was added to the cells and allowed to incubate at room temperature for $5 \mathrm{~min}$. Subsequently, absorbance was measured with a Spectra Max 340PC ELISA reader (Molecular Devices) set at an absorbance wavelength of $570 \mathrm{~nm}$.

2.11. Statistical Analysis. For the above functional experiments, the results were expressed as means \pm standard error of the mean (SEM). Student's $t$-tests were used to analyze the data. Statistical significance was set at $P<0.05$.

\section{Results}

3.1. Rosiglitazone Blocked LPS-Induced NO Release and PGE Production in RAW 264.7 Cells. LPS significantly enhanced $\mathrm{NO}$ release and $\mathrm{PGE}_{2}$ production at $24 \mathrm{~h}$ (Figure $1(\mathrm{a})$ ) and induced the expression of iNOS at $24 \mathrm{~h}$ and COX-2 at $3 \mathrm{~h}$ posttreatment in RAW 264.7 cells (Figure 1(b)). Pretreatment with rosiglitazone (between 1 and $25 \mu \mathrm{M}$ ) significantly blocked LPS-induced NO release and $\mathrm{PGE}_{2}$ production. The levels of expression of iNOS and COX-2 were also reduced in the presence of $25 \mu \mathrm{M}$ rosiglitazone (Figure 1).

3.2. Pretreatment with PPAR $\gamma$ Antagonist Did Not Reverse the Inhibitory Effect of Rosiglitazone on LPS-Induced NO Release and $P G E_{2}$ Production. We further investigated the antiinflammatory effect of rosiglitazone by focusing on PPAR $\gamma$. PPAR $\gamma$ antagonist GW9622 was added to cells for $30 \mathrm{~min}$ before treatment with rosiglitazone. Upon LPS stimulation, GW9622 $(10 \mu \mathrm{M})$ did not reverse the ability of rosiglitazone to block $\mathrm{NO}$ release and $\mathrm{PGE}_{2}$ production. This result indicates that anti-inflammatory effect of rosiglitazone is not mediated through PPAR $\gamma$ (Figure 2).

3.3. PTEN Knockdown in RAW 264.7 Cells Blocked the Inhibitory Effects of Rosiglitazone on LPS-Induced NO Release and $P G E_{2}$ Production. RAW 264.7 cells were transduced either with shLuc or shPTEN viral particles. The knockdown of PTEN by shPTEN in RAW 264.7 cells was confirmed by Western blotting (Figure 3(a)). Like untransduced RAW 264.7 cells treated with LPS, similar inhibitory effects of rosiglitazone on $\mathrm{NO}$ release and $\mathrm{PGE}_{2}$ production were observed in shLuc cells (Figures 3(a) and 3(b)). On the contrary, rosiglitazone at $25 \mu \mathrm{M}$ did not block LPS-induced expressions of iNOS (Figure 3(a)) and COX-2 (Figure 3(b)) in shPTEN cells.

$\mathrm{NO}$ release and $\mathrm{PGE}_{2}$ production in shLuc- and shPTEN cells subjected to LPS stimulation were also compared. Upon LPS stimulation, significantly higher production of NO and $\mathrm{PGE}_{2}$ was observed in shLuc cells than in shPTEN cells. Compared to the control, untreated cells, LPS markedly increased NO release by $11.5 \pm 1.2$ fold in shLuc cells, but only by $1.6 \pm 0.1$ fold in shPTEN cells. Also, $\mathrm{PGE}_{2}$ production was increased by $2.8 \pm 0.6$ fold in shLuc cells, compared to $1.3 \pm 0.1$ fold in shPTEN cells. Moreover, as shown in Figures 3(b) and 3(c), there was no significant difference in $\mathrm{NO}$ release and $\mathrm{PGE}_{2}$ production between LPS-treated and rosiglitazone-pretreated shPTEN cells: NO release $(1.6 \pm 0.1$ fold versus $1.1 \pm 0.4$ fold, $P=0.1152)$ and $\mathrm{PGE}_{2}$ production $(1.3 \pm 0.1$ fold versus $1.4 \pm 0.2$ fold, $P=0.2016)$. Notably, for shPTEN cells, rosiglitazone alone did not inhibit the basal iNOS and COX-2 expression nor $\mathrm{NO}$ and $\mathrm{PGE}_{2}$ production in the absence of LPS stimulation (Figures 3(b) and 3(c)).

3.4. Rosiglitazone Inhibited LPS-Induced Phosphorylation of Akt in shLuc Cells but Not in shPTEN Cells. In shLuc cells, 

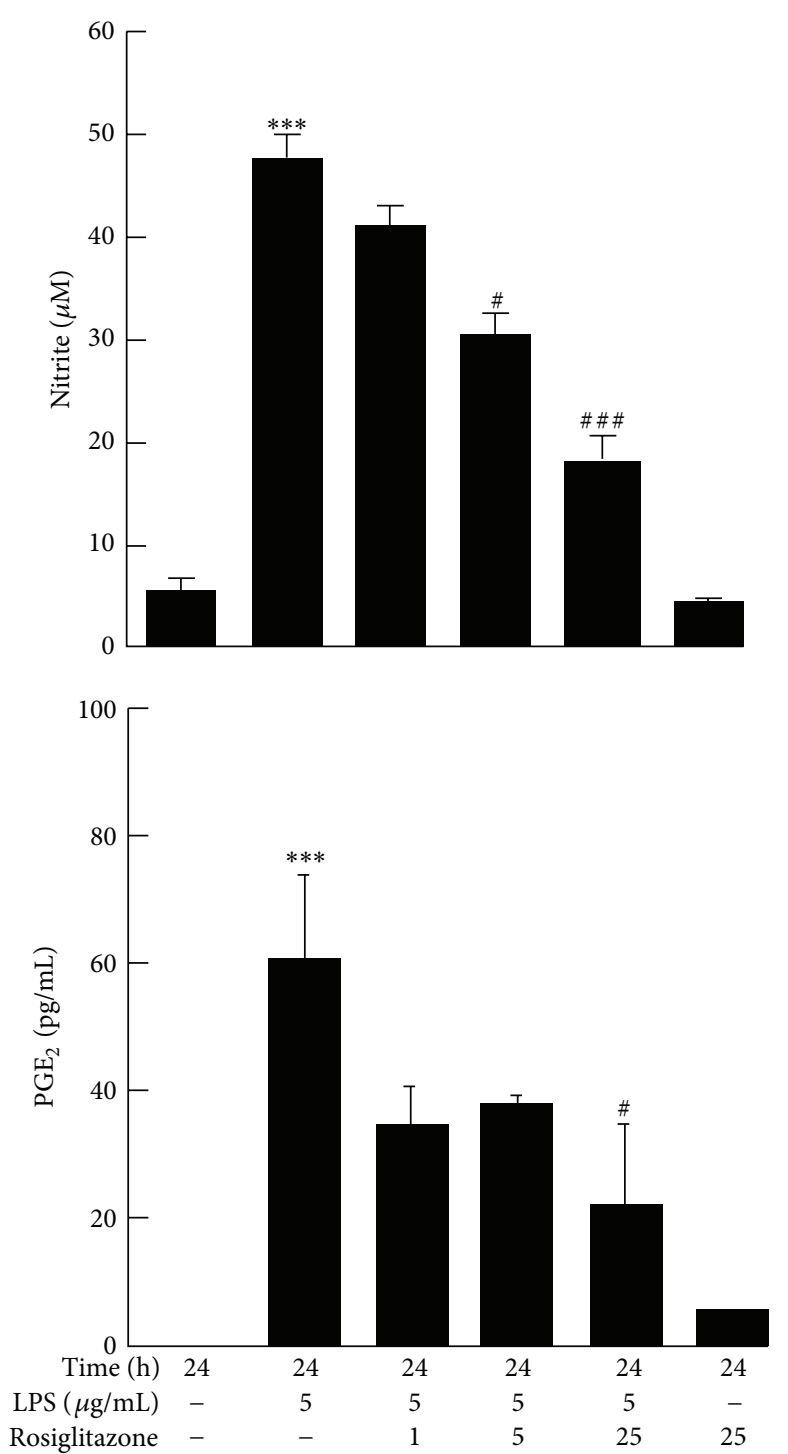

$(\mu \mathrm{M})$

(a)

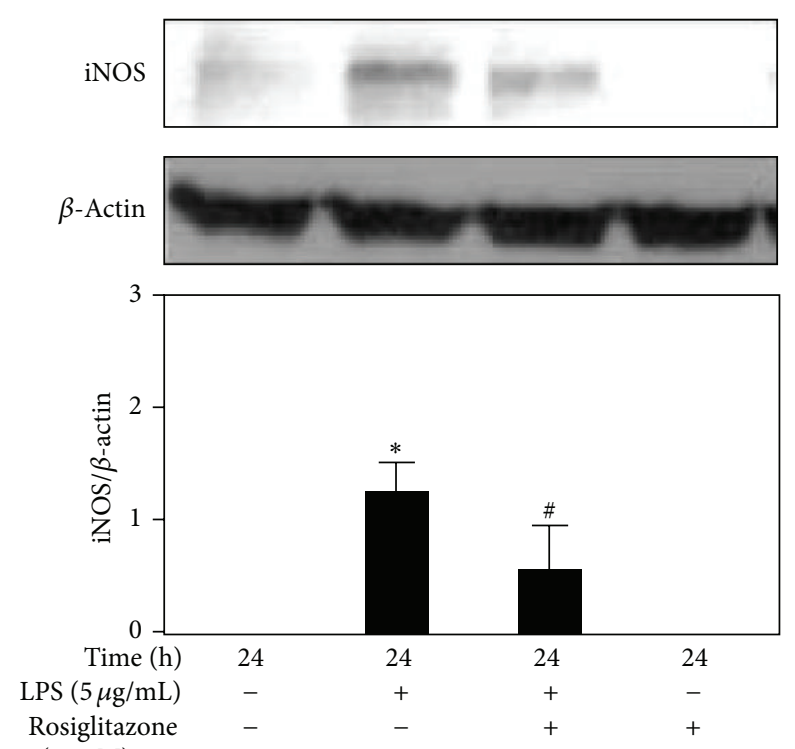

$(25 \mu \mathrm{M})$
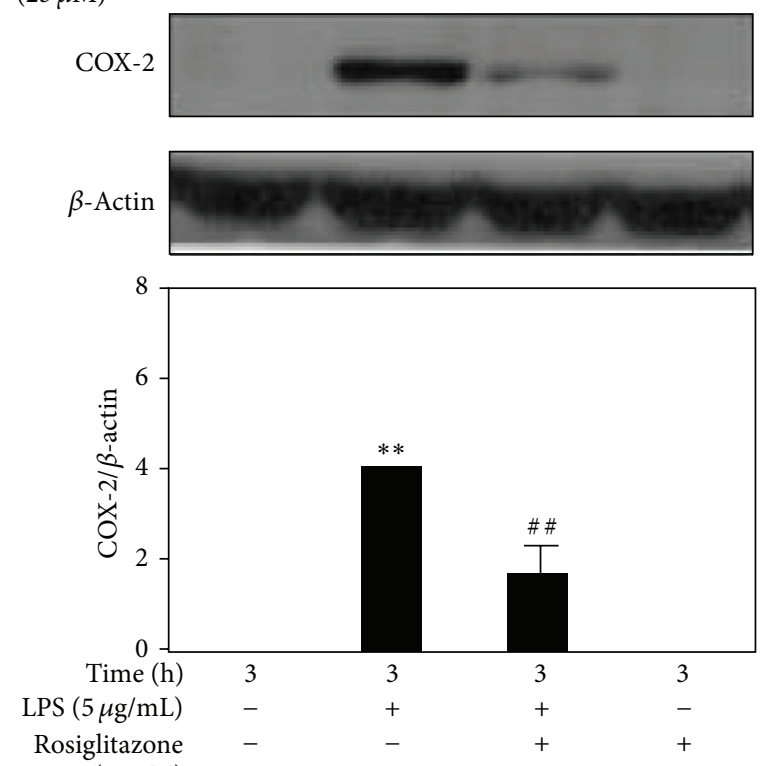

$(25 \mu \mathrm{M})$

(b)

FIGURE 1: Effects of rosiglitazone on LPS-induced NO release and $\mathrm{PGE}_{2}$ production (a) and the expressions of iNOS and COX-2 (b) in RAW 264.7 cells. Cells were treated with 1,5 , or $25 \mu \mathrm{M}$ rosiglitazone for $30 \mathrm{~min}$ before being stimulated with $5 \mu \mathrm{g} / \mathrm{mL}$ LPS for indicated times. Cell supernatants were collected for determining NO release and $\mathrm{PGE}_{2}$ production. Cell lysates were harvested for detecting the levels of iNOS, COX- 2 and $\beta$-actin by Western blot. Data shown are representative of three individual experiments. Data are expressed as mean \pm SEM obtained from three individual cell cultures. ${ }^{*} P<0.05$ and ${ }^{* * *} P<0.001$ compared with the control, untreated group. ${ }^{\#} P<0.05$, ${ }^{\# \#} P<0.01$, and ${ }^{\# \# \# ~} P<0.001$ compared with the LPS group.

LPS increased the phosphorylation of Akt (Ser473) after $15 \mathrm{~min}$. The addition of $25 \mu \mathrm{M}$ rosiglitazone, however, could inhibit Akt phosphorylation (Figure 4). A similar result was observed in untransduced RAW cells (data not shown). Compared with shLuc cells, shPTEN cells had a higher basal level of Akt phosphorylation. When shPTEN cells were treated with LPS, no further increase in Akt phosphorylation was observed. On the other hand, rosiglitazone slightly, but not significantly, inhibited LPS-induced Akt phosphorylation in shPTEN cells. However, rosiglitazone alone did not inhibit Akt phosphorylation in the absence of LPS stimulation.

\subsection{Rosiglitazone Did Not Affect LPS-Induced Phosphorylation} of MAPK Family of Proteins and ROS Generation in shLuc and shPTEN Cells. In addition to activating Akt, LPS increased the phosphorylation of p38 MAPK (Thr180/Tyr182), ERK1/2 (Thr202/Tyr204), and JNK (Thr183/Tyr185) after $15 \mathrm{~min}$ in shLuc cells. On the other hand, rosiglitazone alone $(25 \mu \mathrm{M})$ 


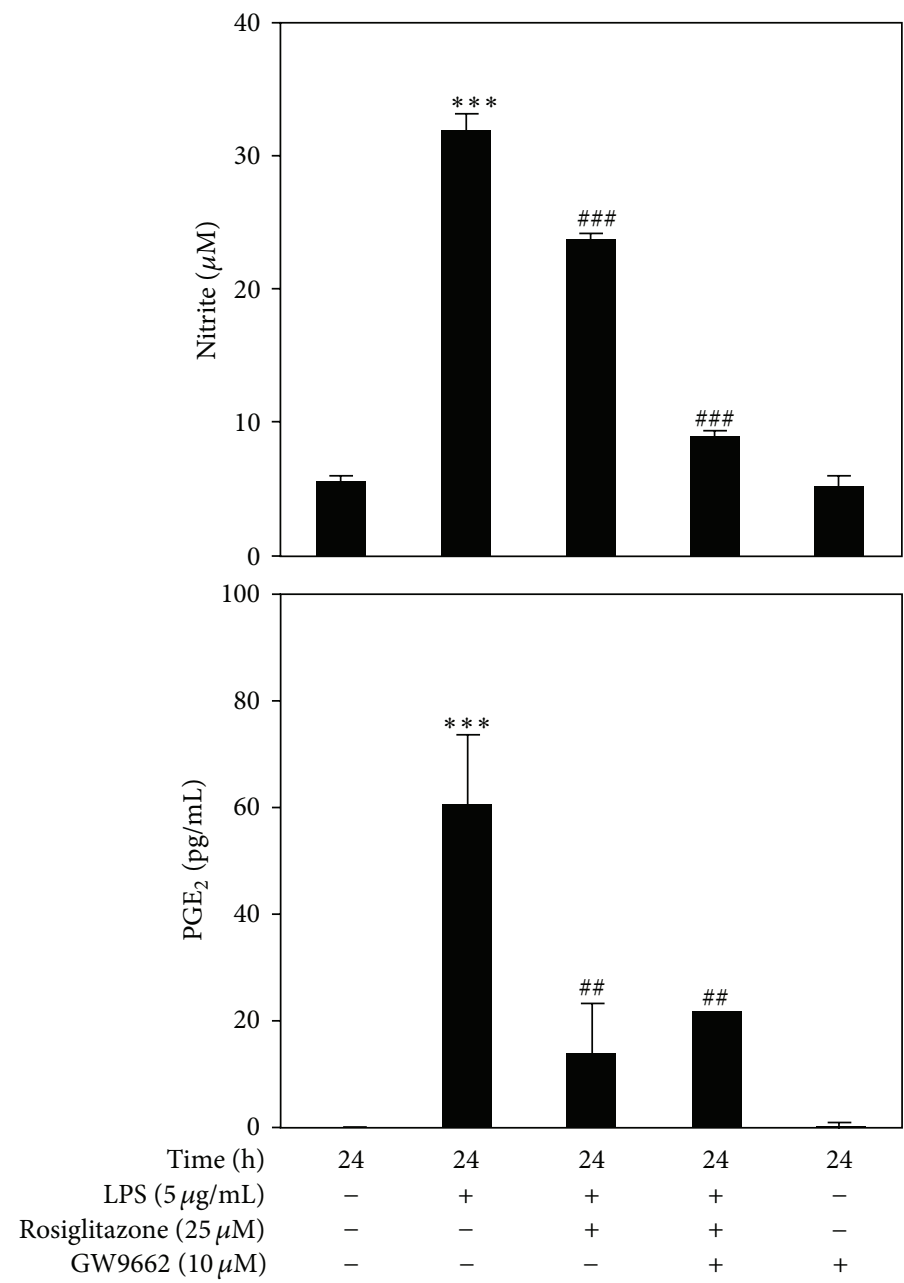

FIGURE 2: Pretreatment with PPAR $\gamma$ antagonist did not reverse the inhibition of rosiglitazone on LPS-induced NO release and PGE 2 production. RAW 264.7 cells were treated with $25 \mu \mathrm{M}$ rosiglitazone for $30 \mathrm{~min}$ before being stimulated with $5 \mu \mathrm{g} / \mathrm{mL} \mathrm{LPS}$ for $24 \mathrm{~h}$. In some experiments, the cells were first treated with $10 \mu \mathrm{M}$ GW9662 for $30 \mathrm{~min}$, prior to the addition of $25 \mu \mathrm{M}$ rosiglitazone for $30 \mathrm{~min}$, and then followed by incubation with $5 \mu \mathrm{g} / \mathrm{mL}$ LPS for $24 \mathrm{~h}$. Cell supernatants were collected for determining NO release and PGE 2 production. Data shown are representative of three individual experiments. Data are expressed as mean \pm SEM obtained from three individual cultures. ${ }^{* * *} P<$ 0.001 compared with the control, untreated group. ${ }^{\# \#} P<0.01$ and ${ }^{\# \#} P<0.001$ compared with the LPS group.

did not affect the phosphorylation levels of the MAPK family of proteins (Figure 5). When shPTEN cells were treated with LPS, no significant increase in the phosphorylation of the MAPK family of proteins was observed. Similarly, rosiglitazone did not have any effect on the phosphorylation of these proteins upon LPS stimulation (Figure 5). Knockdown of PTEN appeared to decrease the basal level of phosphoERK1/2 while increasing phospho-p38 MAPK.

Flow cytometry analysis indicated that LPS stimulated ROS generation, whereas rosiglitazone slightly, but not significantly, inhibited ROS generation in shLuc cells after $3 \mathrm{~h}$ (Figure 6) and $24 \mathrm{~h}$ (data not shown) of treatment. Compared with shLuc cells, shPTEN cells had a significantly higher basal level of ROS. In shPTEN cells, LPS treatment did not lead to higher production of ROS. Rosiglitazone treatment also did not affect ROS production in shPTEN cells with or without LPS stimulation.
3.6. Effect of Higher Doses of Rosiglitazone on NO Release, PGE 2 Production, and 338 MAPK, Akt, ERK1/2, and JNK Phosphorylation in shPTEN Cells. For shPTEN cells, exposure to $25 \mu \mathrm{M}$ rosiglitazone did not significantly reduce NO release (Figure $7(\mathrm{a})$ ) and $\mathrm{PGE}_{2}$ production (Figure $7(\mathrm{~b})$ ). However, higher doses of rosiglitazone at 50 and $100 \mu \mathrm{M}$ did not further affect the reduction of $\mathrm{NO}$ release and $\mathrm{PGE}_{2}$ production. In addition, protein expression of iNOS and COX-2 was no changed by higher doses of rosiglitazone. Furthermore, higher doses of rosiglitazone appeared to decrease the phosphorylation of p38 MAPK. They did not significantly affect the phosphorylation of Akt, ERK1/2, and JNK (Figure 7(c)).

3.7. Higher Doses of Rosiglitazone Inhibited ROS Generation and Cell Growth in shPTEN Cells. Flow cytometry analysis revealed that rosiglitazone at $100 \mu \mathrm{M}$ inhibited markedly ROS 

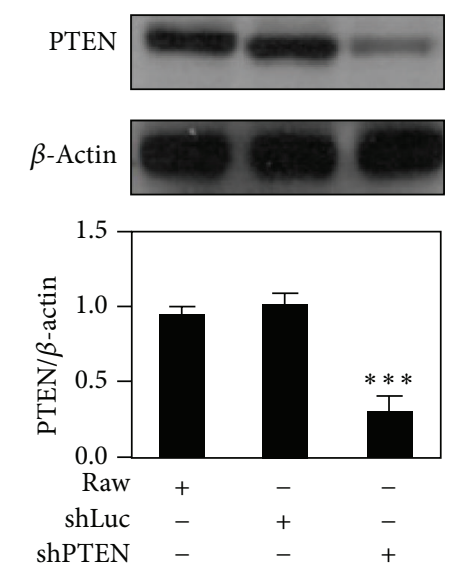

(a)
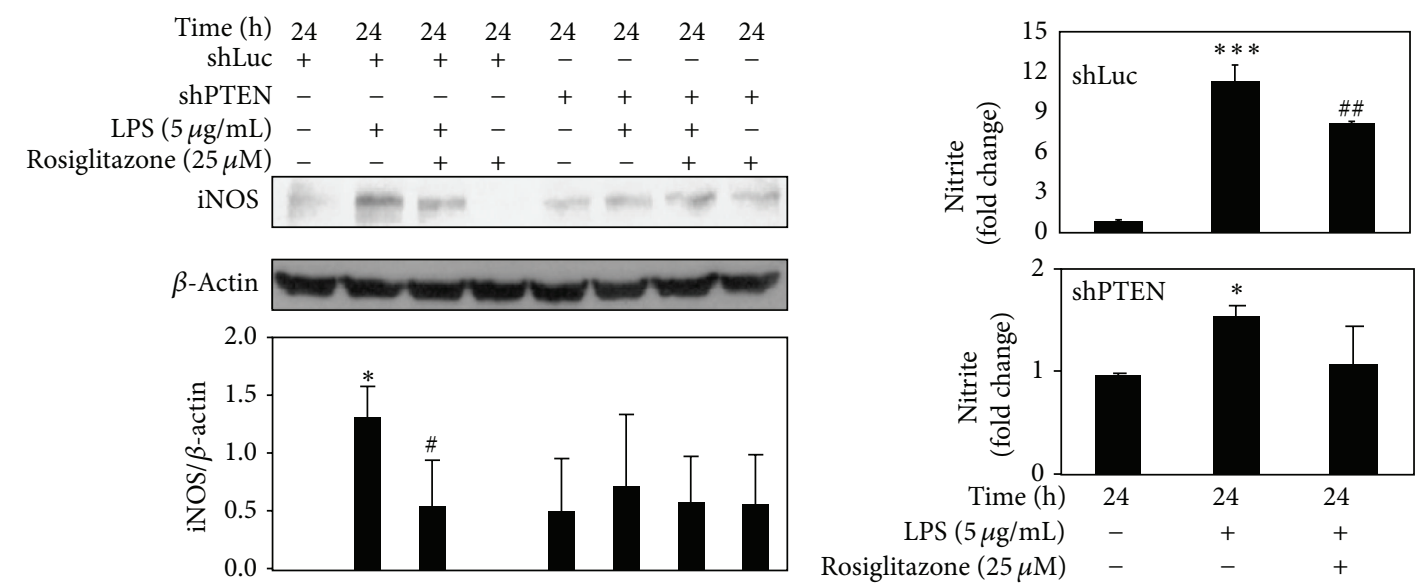

(b)

$\begin{array}{rccccccccc}\text { Time }(\mathrm{h}) & 3 & 3 & 3 & 3 & 3 & 3 & 3 & 3 \\ \text { shLuc } & + & + & + & + & - & - & - & - \\ \text { shPTEN } & - & - & - & - & + & + & + & + \\ \text { LPS }(5 \mu \mathrm{g} / \mathrm{mL}) & - & + & + & - & - & + & + & - \\ \text { Rosiglitazone }(25 \mu \mathrm{M}) & - & - & + & + & - & - & + & +\end{array}$
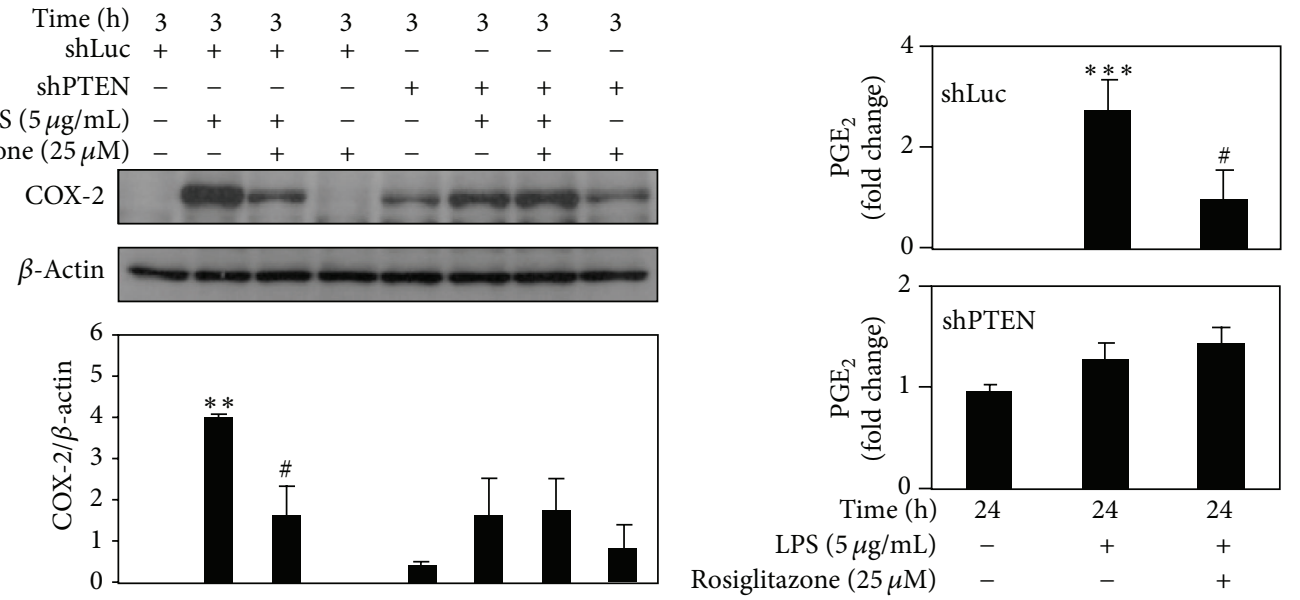

(c)

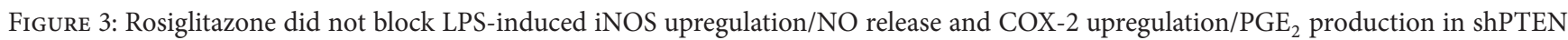
cells. Cells were pretreated with $25 \mu \mathrm{M}$ rosiglitazone prior to stimulation with $5 \mu \mathrm{g} / \mathrm{mL}$ LPS for indicated times. (a) PTEN protein expression in RAW 264.7 cells transduced with shLuc and shPTEN. Effects of rosiglitazone on the expression of iNOS (b) and COX-2 (c) in shLuc and shPTEN cells. Cell lysates were harvested for detection of levels of PTEN, iNOS, COX-2, and $\beta$-actin by Western blotting. Cell supernatants were collected for determining $\mathrm{NO}$ release and $\mathrm{PGE}_{2}$ production. Data shown are representative of three individual experiments. Data are expressed as mean \pm SEM obtained from three individual cultures. ${ }^{*} P<0.05,{ }^{* *} P<0.01$, and ${ }^{* * *} P<0.001$ compared with the control, untreated group. ${ }^{\#} P<0.05$ and ${ }^{\# \#} P<0.01$ compared with the LPS group. 


$\begin{array}{rcccccccc}\text { Time }(\min ) & 15 & 15 & 15 & 15 & 15 & 15 & 15 & 15 \\ \text { shLuc } & + & + & + & + & - & - & - & - \\ \text { shPTEN } & - & - & - & - & + & + & + & + \\ \text { LPS }(5 \mu \mathrm{g} / \mathrm{mL}) & - & + & + & - & - & + & + & - \\ \begin{array}{c}\text { Rosiglitazone } \\ (25 \mu \mathrm{M})\end{array} & - & - & + & + & - & - & + & +\end{array}$
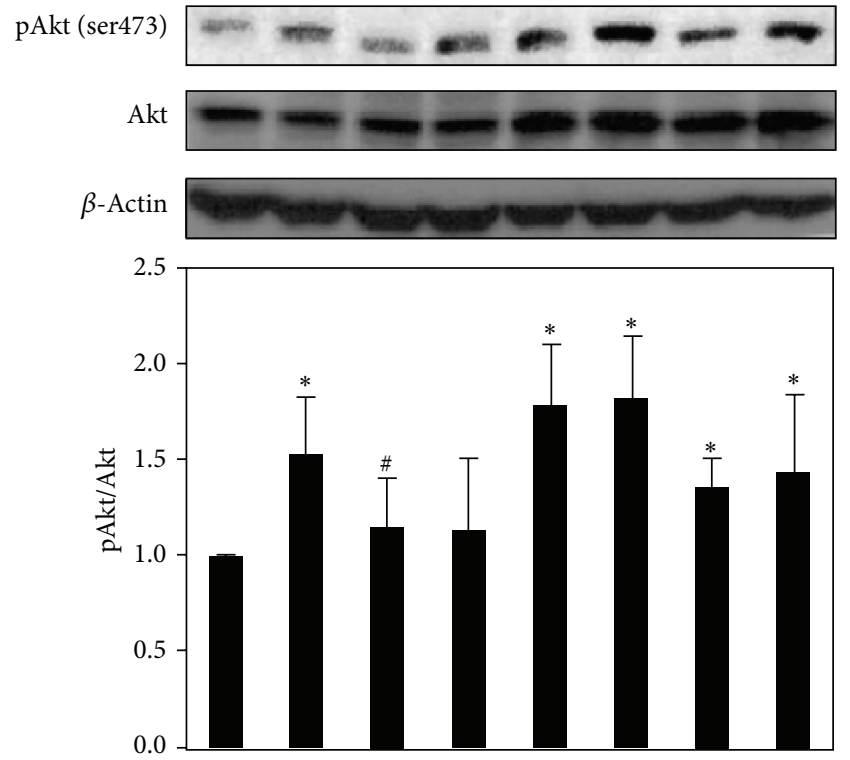

FIGURE 4: Effects of rosiglitazone on Akt phosphorylation in shLuc and shPTEN cells. Cells were treated with $25 \mu \mathrm{M}$ rosiglitazone prior to incubation with $5 \mu \mathrm{g} / \mathrm{mL}$ LPS for $15 \mathrm{~min}$. Cell lysates were harvested for determining the levels of phospho-Akt, Akt, and $\beta$ actin by Western blotting. Data shown are representative of three individual experiments. Data are expressed as mean \pm SEM obtained from three individual cultures. ${ }^{*} P<0.05$ compared with the control, untreated group. ${ }^{\#} P<0.05$ compared with the LPS group.

generation after one day of treatment (Figure 8(a)). Cell cycle analysis was also carried out by measuring the percentages of cells in sub G1-, G0/G1-, and S plus G2/M-phases. Rosiglitazone was found to cause G1 arrest to $70.2 \pm 1.9 \%$ of the cells compared to $51.2 \pm 0.1 \%$ for control, untreated cells. A lower percentage of the treated cells were found to exist in S plus G2/M phase $(27.6 \pm 1.2 \%)$ compared to the control, untreated cells (48.5 $\pm 0.1 \%$; Figure $8(\mathrm{~b})$ ). Cell proliferation was assessed by the MTT assay. The results indicated that shPTEN cells had a significant higher rate of proliferation compared to shLuc cells. Addition of rosiglitazone $(100 \mu \mathrm{M})$ appeared to reduce cell proliferation by $36.4 \%$ by Day 2 (Figure $8(\mathrm{c})$ ).

\section{Discussion}

In our study, LPS significantly induced $\mathrm{NO}$ release and $\mathrm{PGE}_{2}$ production in RAW 264.7 cells, and these processes were inhibited by rosiglitazone. In addition, the anti-inflammatory effect of rosiglitazone appeared to involve the inactivation of Akt that was independent of $\operatorname{PPAR} \gamma$. These results are consistent with previous studies utilizing PPAR $\gamma$ ligands in primary rat astrocytes, osteoblast-like cells MC3T3E-1, and RAW 264.7 cells [11, 27, 28]. Moreover, we have demonstrated that PTEN-deficient cells had higher basal ROS production, elevated inflammatory mediator secretion, and increased tumor cell growth, as well as enhanced activation of Akt and p38 MAPK and decreased activation of ERK1/2. Furthermore, rosiglitazone caused growth inhibition by promoting G1 arrest and decreasing cells in S plus G2/M phases via inhibiting p38 MAPK activation and ROS production. However, rosiglitazone did not alter the enhanced production of $\mathrm{NO}$ and $\mathrm{PGE}_{2}$ in PTEN-deficient cells (Figure 9).

In the pathogenesis of cancer and inflammation, ROS acts as a double-edged sword to regulate signaling molecules [17]. A previous study has reported that activation of PPAR $\gamma$ nuclear receptor by synthetic 15-J2-cyclopentenone isoprostanes could markedly inhibit iNOS and COX-2 expression via a partial redox-dependent mechanism [28]. However, we found that the anti-inflammatory effect of rosiglitazone on LPS-stimulated RAW 264.7 cells was not modulated by inhibition of ROS production. This discrepancy may be due to different stimulators being used and different assay time points. Besides, PTEN also controls inflammation and cancer, especially in the liver diseases [29]. This regulation appears to involve ROS modulation of the proapoptotic and procell survival proteins [30, 31]. Endogenously produced ROS has been shown to inactivate PTEN in a macrophage cell line [32]. The ROS-mediated breast cancer cell proliferation was found to be related to the activation of PI3K pathway and reduction of PTEN activity [33]. PTEN inactivation by alkylation of PTEN activates Akt in HEK-293 human embryonic kidney cells [34]. In our study, higher basal ROS production and activation of Akt were observed in PTENdeficient cells to promote inflammation and cell growth. However, rosiglitazone did not block the increased levels of $\mathrm{NO}$ and $\mathrm{PGE}_{2}$ in PTEN-deficient cells, whereas high dosage of rosiglitazone inhibited ROS generation to reduce cell growth. Our results implied that ROS could serve different functions including PTEN-regulated anti-inflammatory property and growth inhibition by rosiglitazone.

We have also pointed out that PTEN-deficient cells without extrinsic inflammatory stimulation could develop augmented inflammatory response and ROS production to accelerate cell growth. This likely involved altered activation of signaling molecules including Akt, p38 MAPK, and ERK1/2. Our results were consistent in part with a previous study which showed that PTEN-deficient human mast cells displayed constitutive activation of Akt, p38 MAPK, and JNK to promote cytokine secretion and cell survival [35]. Hepatic steatosis, inflammation, and even carcinogenesis were observed in PTEN-deficient mice [36]. PTEN deficiency has been shown to result in steatohepatitis and hepatic tumorigenesis due to ROS generation and abnormal activations of PKB/Akt and ERK1/2 [37]. Compared to the control shLuc cells, PTEN knockdown caused reduced inflammation response to LPS induction and enhanced activation of Akt (Figures 3 and 4). Similarly, a previous study had shown that PTEN-deficient cells had reduced inflammatory cytokine production in response to gram-negative bacteria and LPS [38]. In our study, we have shown that LPS-induced ROS production was observed in shLuc cells but not in shPTEN cells (Figure 6). Though the precise mechanisms are not understood, this phenomenon may be explained by the fact 


$\begin{array}{rcccccccc}\text { Time }(\mathrm{min}) & 15 & 15 & 15 & 15 & 15 & 15 & 15 & 15 \\ \text { shLuc } & + & + & + & + & - & - & - & - \\ \text { shPTEN } & - & - & - & - & + & + & + & + \\ \text { LPS }(5 \mu \mathrm{g} / \mathrm{mL}) & - & + & + & - & - & + & + & - \\ \text { Rosiglitazone } & - & - & + & + & - & - & + & + \\ (25 \mu \mathrm{M}) & & & & & & & \end{array}$

pERK1/2 (Thr202/Tyr204)
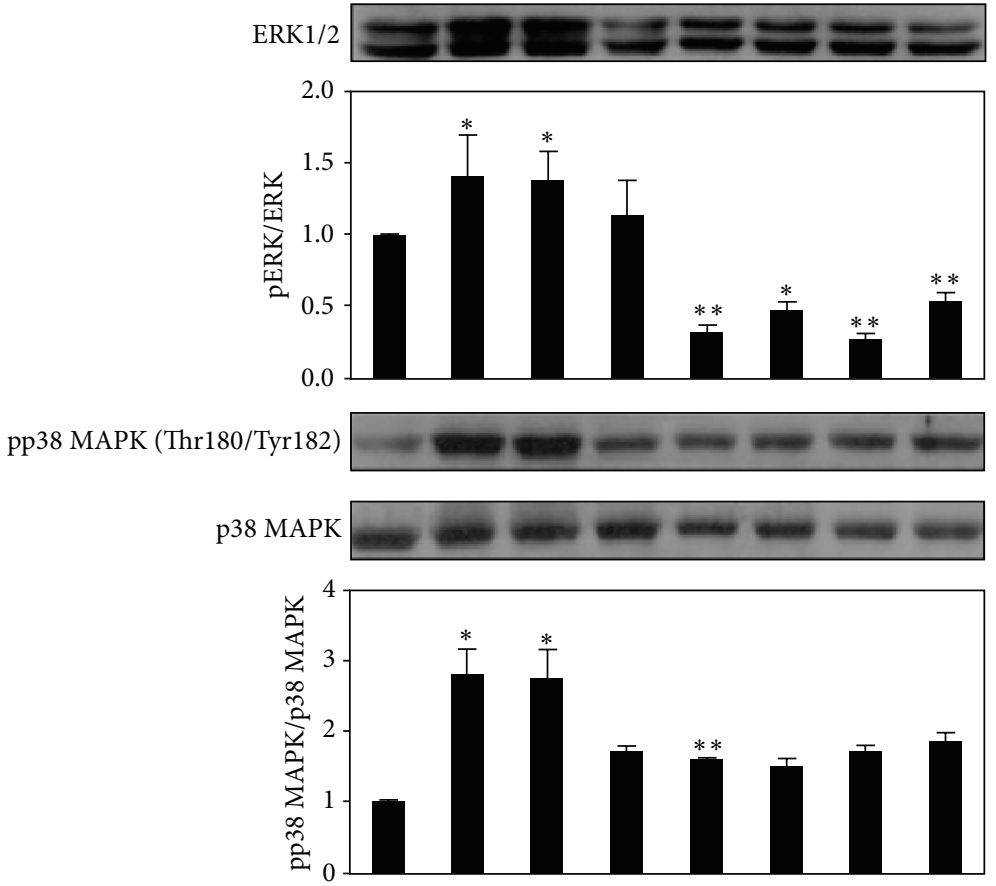

pJNK (Thr183/Tyr185)
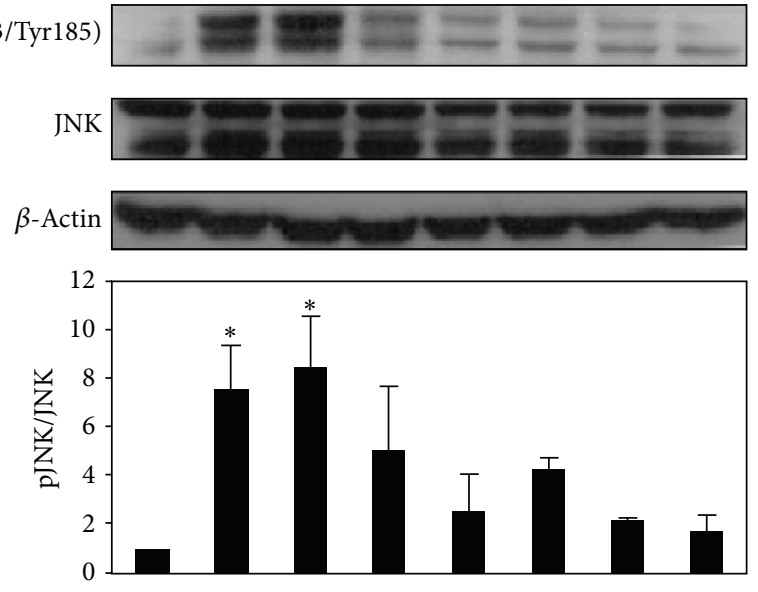

FIGURE 5: Effects of rosiglitazone on phosphorylation of MAPK family of proteins in shLuc and shPTEN cells. Cells were treated with $25 \mu \mathrm{M}$ rosiglitazone prior to stimulation with $5 \mu \mathrm{g} / \mathrm{mL}$ LPS for $15 \mathrm{~min}$. Cell lysates were prepared for determining the levels of phospho-ERK1/2, ERK1/2, phospho-p38 MAPK, p38 MAPK, phospho-JNK, JNK, and $\beta$-actin by Western blotting. Data shown are representative of three individual experiments. Data are expressed as mean \pm SEM obtained from three individual cultures. ${ }^{*} P<0.05$ and ${ }^{* *} P<0.01$ compared with the control, untreated group.

that the shPTEN cells are able to produce continuously higher levels of ROS, which could cause a resistance to extrinsic stimuli that promote ROS generation. Thus, PTEN knockdown attenuates inflammatory responses and enhances tumor cell survival in vivo and in vitro.

Several studies have indicated that alteration in PI3K/Akt and MAPK signaling by PPAR $\gamma$ ligands and its agonists may be responsible for the diminished inflammation and tumorigenesis. Adenovirally expressed PPAR $\gamma$ has been shown to exert inhibitory effect against LPS-induced inflammatory response via suppression of ERK activation in human dental pulp cells [39]. On the other hand, pioglitazone exerted inhibitory effect against LPS-induced inflammatory response in dopaminergic neurons [23] and in microglia [24] 

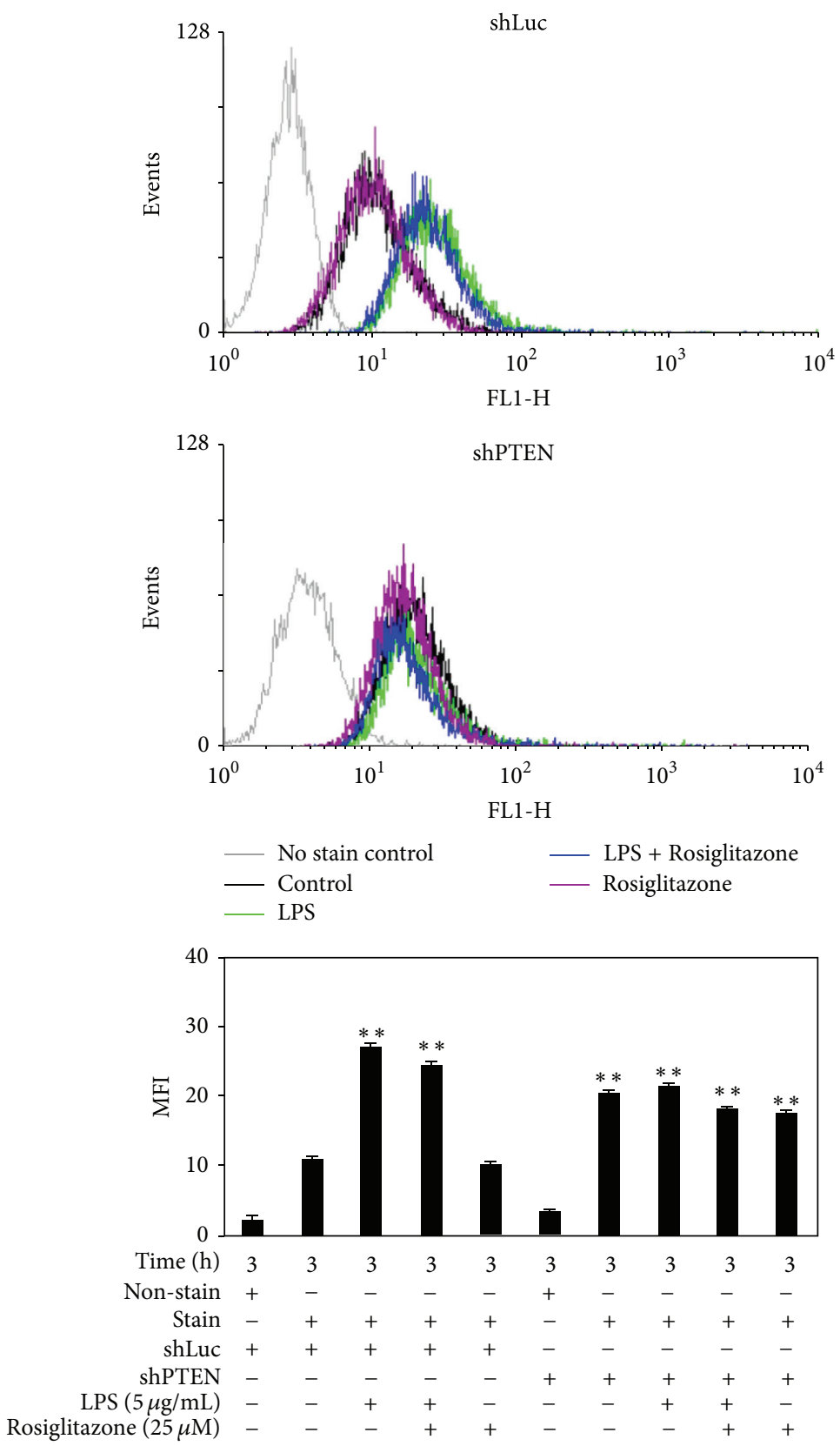

FIGURE 6: Effects of rosiglitazone on ROS generation in shLuc and shPTEN cells. Cells were treated with $25 \mu \mathrm{M}$ rosiglitazone prior to stimulation with $5 \mu \mathrm{g} / \mathrm{mL}$ LPS for $3 \mathrm{~h}$. Cell were harvested, stained with DCFH-DA, and then analyzed by FACScan. Data shown are representative of three individual experiments. Data are expressed as mean \pm SEM obtained from three individual cultures. MFI stands for mean fluorescence intensity. ${ }^{* *} P<0.01$ compared with the control, untreated shLuc cells.

via inhibition of p38 MAPK activity. PPAR $\gamma$ ligands activate ERK1/2 in cancer cell lines, which is associated with antineoplastic actions [25]. A PPAR $\gamma$ ligand 15d-PGJ2 induces apoptosis via increased inhibition of ERK and decreased inhibition of p38 MAPK in MIA PaCa-2 human pancreatic cells [40]. In our study, rosiglitazone at $25 \mu \mathrm{M}$ significantly blocked LPS-induced production of $\mathrm{NO}$ and $\mathrm{PGE}_{2}$, which was related to inhibition of Akt activation in shLuc (Figure 3). Rosiglitazone did not appear to inhibit LPS-induced activation of Akt in shPTEN cells (Figure 4). Rosiglitazone alone did not inhibit the inflammatory response without LPS stimulation. Furthermore, rosiglitazone at $>25 \mu \mathrm{M}$ dosedependently inhibited the activation of p38 MAPK, whereas it did not significantly affect activations of Akt, ERK1/2, and JNK (Figure 7).

Anti-inflammatory actions and protective roles of PPAR $\gamma$ agonists are also mediated via upregulation of PTEN in cigarette smoke-induced mucin production [19] and asthmatic inflammation [20]. Conversely, PPAR $\gamma$-dependent anti-inflammatory action of rosiglitazone suppresses 


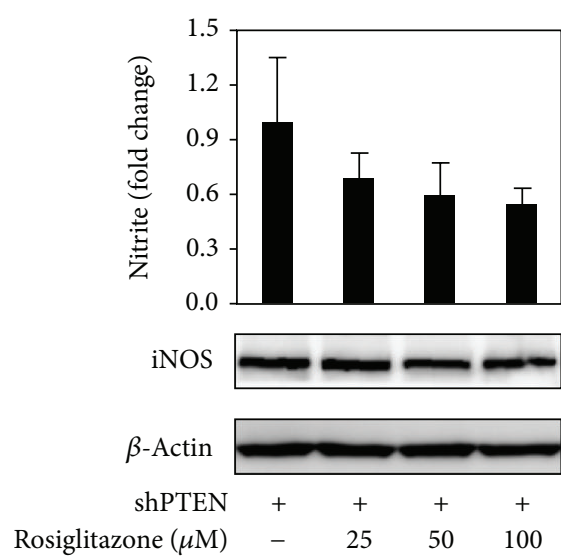

(a)

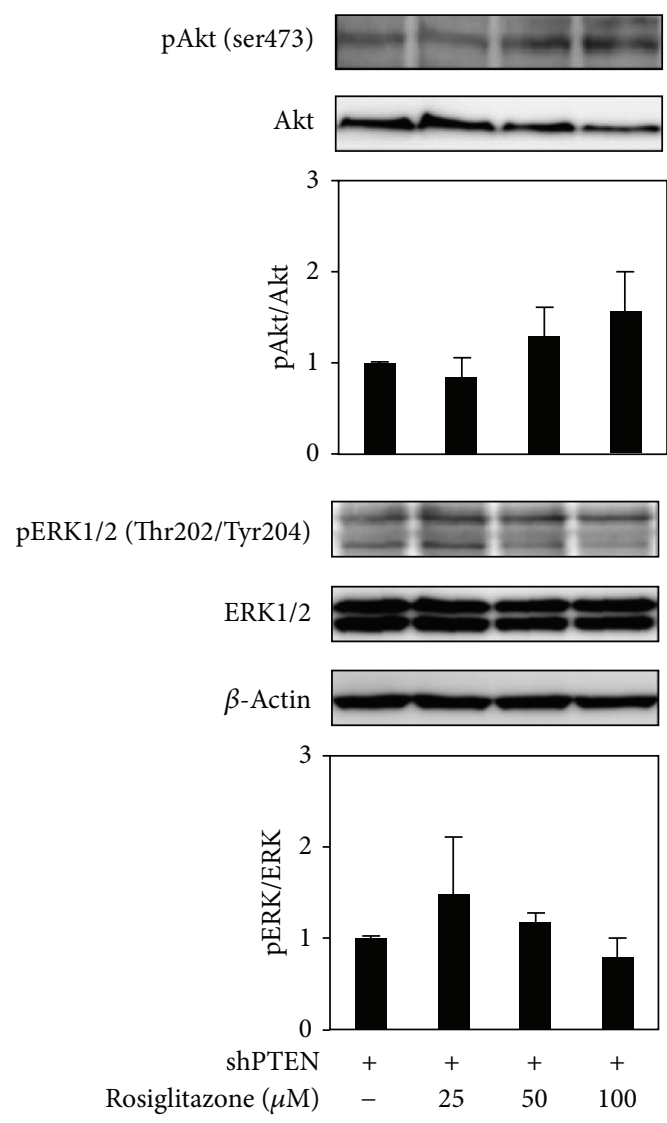

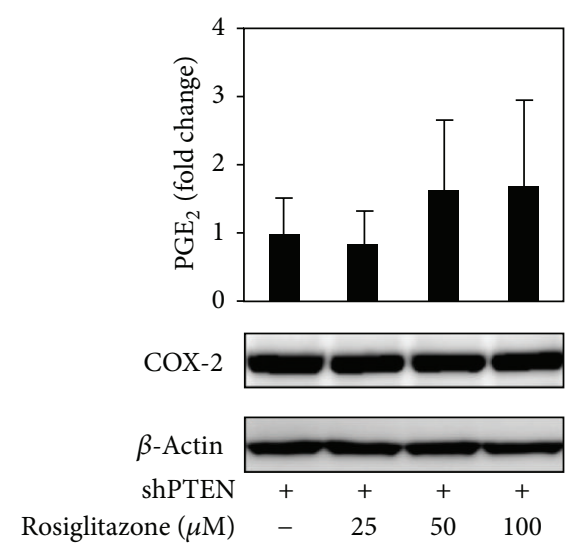

(b)

pp38 MAPK (Thr180/Tyr182)

p38 MAPK
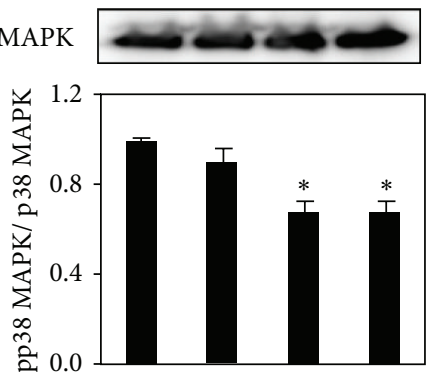

pJNK (Thr183/Tyr185)

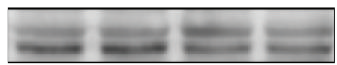

JNK

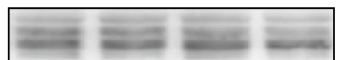

$\beta$-Actin

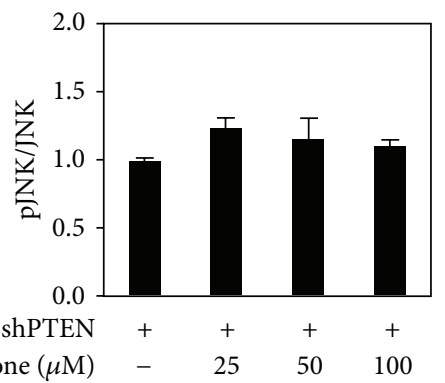

(c)

FIGURE 7: Effects of higher doses $(>25 \mu \mathrm{M})$ of rosiglitazone on inflammatory response in shPTEN cells. Cells were treated with higher doses $(>25 \mu \mathrm{M})$ of rosiglitazone and NO release (a), $\mathrm{PGE}_{2}$ production (b), and activations of Akt and MAPK family of proteins (c) were determined. Cells were treated with rosiglitazone for $24 \mathrm{~h}$. Cell supernatants were collected for measuring NO release and $\mathrm{PGE}_{2}$ production. Cell lysates were harvested for determining the levels of iNOS, COX-2, phospho-Akt, Akt, phospho-p38 MAPK, p38 MAPK, phospho-ERK1/2, ERK1/2, and phospho-JNK, JNK, and $\beta$-actin by Western blotting. Data shown are representative of three individual experiments. Data are expressed as mean \pm SEM obtained from three individual cultures. ${ }^{*} P<0.05$ compared with the control, untreated group.

TNF- $\alpha$ secretion and is not mediated by PTEN in human monocytes [9]. We found that anti-inflammatory actions of rosiglitazone were modulated via upregulation of PTEN in LPS-induced inflammation (Supplementary figure 1 in Supplementary Material available online at http://dx.doi.org/10.1155/2014/787924). However, in our PTEN-deficient cell model, higher dosages of rosiglitazone did not decrease inflammatory response nor activation of Akt, thereby indicating that the anti-inflammatory property of PPAR $\gamma$ agonist rosiglitazone is dependent on PTEN. 


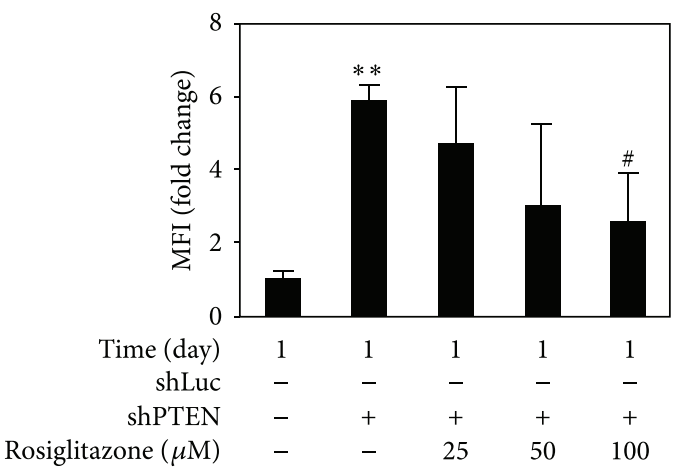

(a)

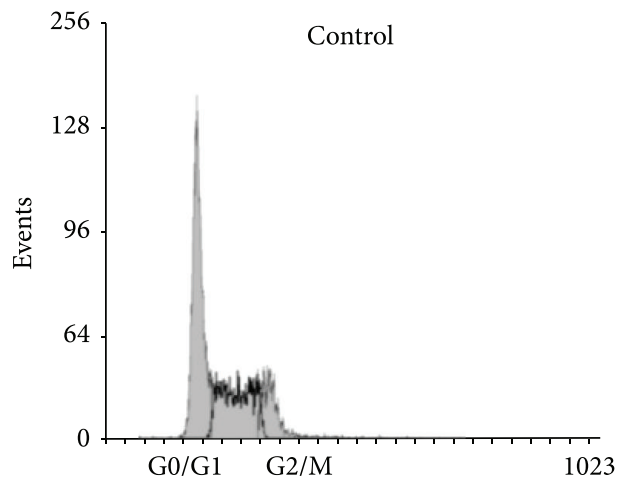

SubG1: $0.4 \pm 0.1$

G0/G1: $51.2 \pm 0.1$

S + G2/M: $48.5 \pm 0.1$

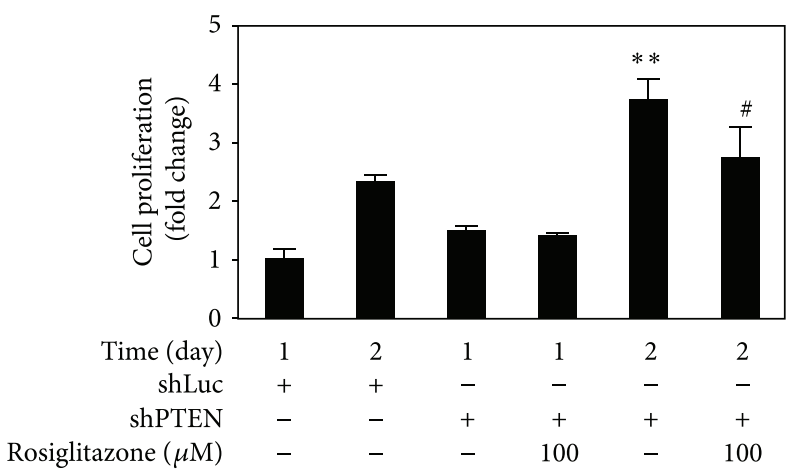

(c)

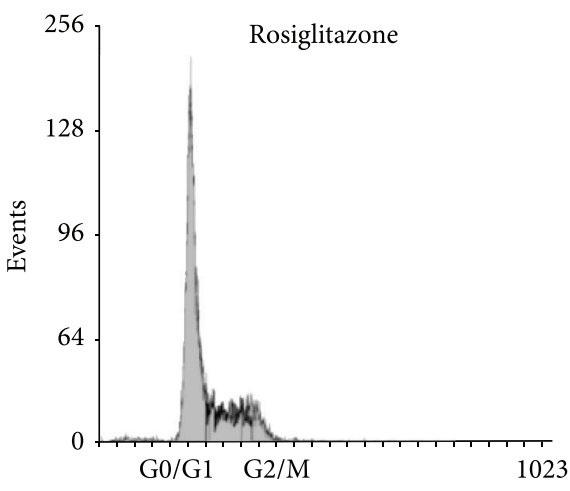

SubG1: $2.2 \pm 0.4$

G0/G1: $70.2 \pm 1.9^{\#}$

$\mathrm{S}+\mathrm{G} 2 / \mathrm{M}: 27.6 \pm 1.2^{\#}$

(b)

FIGURE 8: Higher doses of rosiglitazone inhibited ROS generation and cell growth in shPTEN cells. Rosiglitazone affected ROS generation (a), cell cycle phase distribution (b), and cell proliferation (c). shLuc and shPTEN cells were treated with 25-100 $\mu \mathrm{M}$ rosiglitazone for indicated times. Then, cells were harvested and stained with either DCFH-DA or propidium iodide and analyzed by flow cytometry. Cell growth was determined with the MTT assay kit. Data are expressed as means \pm SEM obtained from three individual cultures. MFI stands for mean fluorescence intensity. ${ }^{* *} P<0.01$ compared with the shLuc cells. ${ }^{*} P<0.05$ compared with the shPTEN cells.

Moreover, our results also indicate that PTEN-deficient cells could counteract anti-inflammatory responses to rosiglitazone because they had a higher basal inflammatory environment. However, the detailed mechanisms required further investigation.

Several studies with cell and animal models have reported that activation of PPAR $\gamma$ could attenuate cellular stress $[41,42]$ and inflammation $[39,43]$ by various stimuli and is concomitant with a reduction of ROS generation. In our study, higher doses of rosiglitazone also inhibited growth inhibition of PTEN-deficient cells via inhibition of ROS production (Figure 8). PPAR $\gamma$ upregulates PTEN expression, which is involved in the inhibition of cell growth and the induction of cell apoptosis in various cancer cells, including hepatocellular carcinoma [44, 45], colon cancer [46], and non-small-cell lung cancer cells (NSCLC) [47]. In addition to PTEN, PPAR $\gamma$ agonist rosiglitazone also downregulates Akt/mTOR/p70S6K signal cascade, which inhibits NSCLC cell proliferation through $\operatorname{PPAR} \gamma$-dependent and $\operatorname{PPAR} \gamma$ independent signaling [48]. However, PPAR $\gamma$ agonists also diminish activation of Akt-1 in 3T3-L1 adipocyte apoptosis without affecting PI3K and PTEN [49]. Rosiglitazoneinduced PTEN expression is accompanied by a decline in activations of Akt and MAPK and a rise in G1 arrest in MCF-7 cells $[26,50]$. In our study, rosiglitazone caused G1 arrest and lowered proportion of cells in S+G2M phase, which resulted in growth inhibition in PTEN-deficient cells. Blockade of ROS generation and inactivation of p38 MAPK were also involved. However, this process was independent of the activations of Akt. Accordingly, the possible mechanisms of interregulation between ROS and p38 MAPK following rosiglitazone are still unclear, though they may play important roles in cell growth in the absence of PTEN.

\section{Conclusion}

Taken together, these results indicate that the antiinflammatory property of rosiglitazone was correlated with the regulation of PTEN. But this effect was independent of the inhibition of ROS. Moreover, rosiglitazone affected 


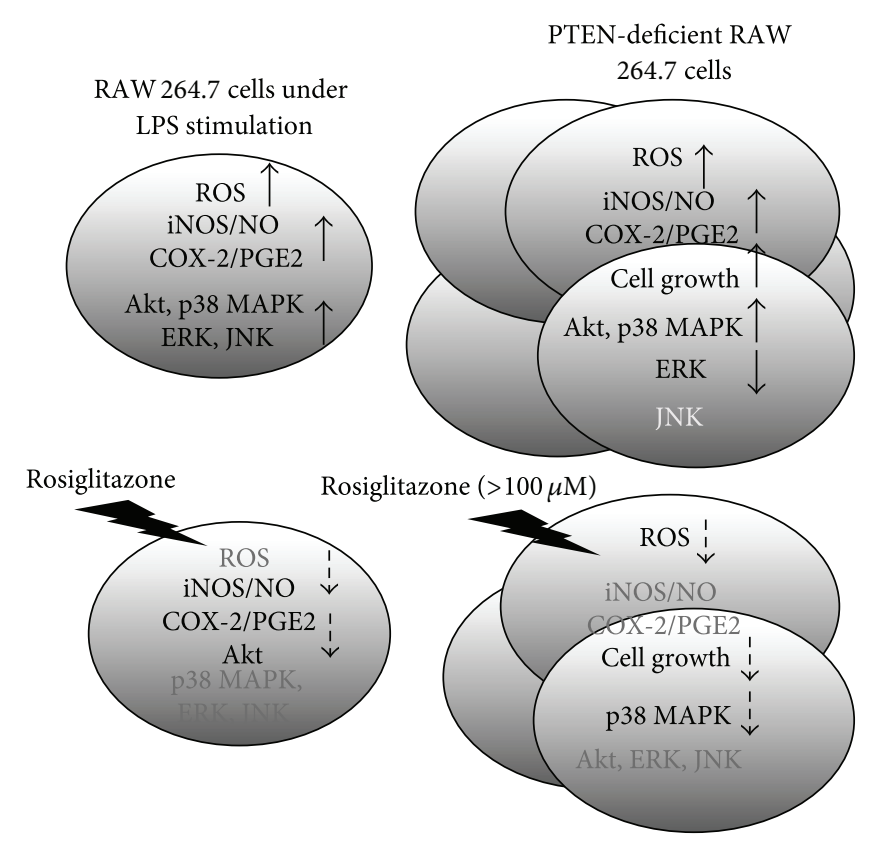

FIGURE 9: A schematic model of the anti-inflammatory and growth inhibitory effects of rosiglitazone in PTEN-deficient RAW 264.7 cells. Lower doses $(<25 \mu \mathrm{M})$ of rosiglitazone inhibited LPS-induced $\mathrm{NO}$ release, $\mathrm{PGE}_{2}$ production, and activation of Akt in RAW 264.7 murine macrophages. These anti-inflammatory effects of rosiglitazone were dependent on PTEN, but they did not affect the production of ROS. In addition to a significantly higher inflammatory response and elevated production of ROS, PTEN knockdown caused increased cell growth and altered signaling molecule expression including Akt, p38 MAPK, and ERK. On the other hand, higher doses $(<100 \mu \mathrm{M})$ of rosiglitazone delayed cell growth inhibition in PTEN-deficient cells through inhibition of ROS production and p38 MAPK activation.

PTEN-deficient cell growth through inhibition of the activation of $\mathrm{p} 38 \mathrm{MAPK}$ and production of ROS.

\section{Conflict of Interests}

The authors declare that they have no conflict of interests.

\section{Authors' Contribution}

Chiou-Feng Lin, Kung-Chia Young and Chyi-Huey Bai contributed equally to this work.

\section{Acknowledgments}

This work was supported by Shin Kong Wu Ho-Su Memorial Hospital (SKH-TMU-101-10) and by Cing Nian Dental Clinic in Taiwan. The authors thank Dr. Chiou-Feng Lin for providing the laboratory facility for some experiments and for his inputs. In addition, they thank Dr. Chiu-Ling Chiang and Dr. $\mathrm{Yi}-\mathrm{Te} \mathrm{Hsu}$ for their inputs and editorial assistance.

\section{References}

[1] J. Roman, "Peroxisome proliferator-activated receptor gamma and lung cancer biology: implications for therapy," Journal of Investigative Medicine, vol. 56, no. 2, pp. 528-533, 2008.

[2] J. R. Weng, C. Y. Chen, J. J. Pinzone, M. D. Ringel, and C. S. Chen, "Beyond peroxisome proliferator-activated receptor $\gamma$ signaling: the multi-facets of the antitumor effect of thiazolidinediones," Endocrine-Related Cancer, vol. 13, no. 2, pp. 401413, 2006.

[3] F. Ondrey, "Peroxisome proliferator-activated receptor $\gamma$ pathway targeting in carcinogenesis: implications for chemoprevention," Clinical Cancer Research, vol. 15, no. 1, pp. 2-8, 2009.

[4] Y. Q. Chen, I. J. Edwards, S. J. Kridel, T. Thornburg, and I. M. Berquin, "Dietary fat-gene interactions in cancer," Cancer and Metastasis Reviews, vol. 26, no. 3-4, pp. 535-551, 2007.

[5] T. Shiojiri, K. Wada, A. Nakajima et al., "PPAR $\gamma$ ligands inhibit nitrotyrosine formation and inflammatory mediator expressions in adjuvant-induced rheumatoid arthritis mice," European Journal of Pharmacology, vol. 448, no. 2-3, pp. 231238, 2002.

[6] A. von Knethen, M. Soller, and B. Brüne, "Peroxisome proliferator-activated receptor $\gamma$ (PPAR $\gamma$ ) and sepsis," Archivum Immunologiae et Therapiae Experimentalis, vol. 55, no. 1, pp. 1925, 2007.

[7] K. Celiński, A. Madro, B. Prozorow-Król et al., "Rosiglitazone, a peroxisome proliferator-activated receptor gamma (PPAR $\gamma)$ specific agonist, as a modulator in experimental acute pancreatitis," Medical Science Monitor, vol. 15, no. 1, pp. BR21-BR29, 2009.

[8] A. P. Woster and C. K. Combs, "Differential ability of a thiazolidinedione PPAR $\gamma$ agonist to attenuate cytokine secretion in primary microglia and macrophage-like cells," Journal of Neurochemistry, vol. 103, no. 1, pp. 67-76, 2007.

[9] G. Hong, B. Davis, N. Khatoon, S. F. Baker, and J. Brown, "PPAR $\gamma$-dependent anti-inflammatory action of rosiglitazone in human monocytes: suppression of TNF $\alpha$ secretion is not mediated by PTEN regulation," Biochemical and Biophysical Research Communications, vol. 303, no. 3, pp. 782-787, 2003.

[10] C. A. Meier, R. Chicheportiche, C. E. Juge-Aubry, M. G. Dreyer, and J.-M. Dayer, "Regulation of the interleukin-1 receptor antagonist in THP-1 cells by ligands of the peroxisome proliferator-activated receptor $\gamma$," Cytokine, vol. 18, no. 6, pp. 320-328, 2002.

[11] S. Giri, R. Rattan, A. K. Singh, and I. Singh, "The 15-deoxy$\delta 12,14$-prostaglandin $\mathrm{J} 2$ inhibits the inflammatory response in primary rat astrocytes via down-regulating multiple steps in phosphatidylinositol 3-kinase-akt-NF- $\kappa$ B-p300 pathway independent of peroxisome proliferator-activated receptor $\gamma$," Journal of Immunology, vol. 173, no. 8, pp. 5196-5208, 2004.

[12] J. Drzewoski, A. Drozdowska, and A. Śliwińska, "Do we have enough data to confirm the link between antidiabetic drug use and cancer development?" Polskie Archiwum Medycyny Wewnetrznej, vol. 121, no. 3, pp. 81-87, 2011.

[13] T. Maehama and J. E. Dixon, "The tumor suppressor, PTEN/MMAC1, dephosphorylates the lipid second messenger, phosphatidylinositol 3,4,5-trisphosphate," Journal of Biological Chemistry, vol. 273, no. 22, pp. 13375-13378, 1998.

[14] B. H. Jiang and L. Z. Liu, "Chapter 2 PI3K/PTEN signaling in angiogenesis and tumorigenesis," Advances in Cancer Research, vol. 102, pp. 19-65, 2009. 
[15] M. L. Slattery, J. S. Herrick, A. Lundgreen, F. A. Fitzpatrick, K. Curtin, and R. K. Wolff, "Genetic variation in a metabolic signaling pathway and colon and rectal cancer risk: mTOR, PTEN, STK11, RPKAA1, PRKAG2, TSC1, TSC2, PI3K and Akt1," Carcinogenesis, vol. 31, no. 9, pp. 1604-1611, 2010.

[16] M. L. Slattery and F. A. Fitzpatrick, "Convergence of hormones, inflammation, and energy-related factors: a novel pathway of cancer etiology," Cancer Prevention Research, vol. 2, no. 11, pp. 922-930, 2009.

[17] S. C. Gupta, D. Hevia, S. Patchva, B. Park, W. Koh, and B. B. Aggarwal, "Upsides and downsides of reactive oxygen species for Cancer: the roles of reactive oxygen species in tumorigenesis, prevention, and therapy," Antioxidants and Redox Signaling, vol. 16, no. 11, pp. 1295-1322, 2012.

[18] L. Patel, I. Pass, P. Coxon, C. P. Downes, S. A. Smith, and C. H. Macphee, "Tumor suppressor and anti-inflammatory actions of PPAR $\gamma$ agonists are mediated via upregulation of PTEN," Current Biology, vol. 11, no. 10, pp. 764-768, 2001.

[19] S. Y. Lee, E. J. Kang, G. Y. Hur et al., "Peroxisome proliferatoractivated receptor- $\gamma$ inhibits cigarette smoke solution-induced mucin production in human airway epithelial (NCI-H292) cells," American Journal of Physiology, vol. 291, no. 1, pp. L84L90, 2006.

[20] K. S. Lee, S. J. Park, P. H. Hwang et al., "PPAR-gamma modulates allergic inflammation through up-regulation of PTEN," The FASEB Journal, vol. 19, no. 8, pp. 1033-1035, 2005.

[21] Z. Wei-guo, Y. Hui, L. Shan et al., "PPAR- $\gamma$ agonist inhibits Ang II-induced activation of dendritic cells via the MAPK and NF$\kappa \mathrm{B}$ pathways," Immunology and Cell Biology, vol. 88, no. 3, pp. 305-312, 2010.

[22] M. Sánchez-Hidalgo, A. R. Martín, I. Villegas, and C. A. de la Lastra, "Rosiglitazone, a PPAR $\gamma$ ligand, modulates signal transduction pathways during the development of acute TNBSinduced colitis in rats," European Journal of Pharmacology, vol. 562, no. 3, pp. 247-258, 2007.

[23] H. Ji, H. Wang, F. Zhang, X. Li, X. Lu, and A. Shen, "PPAR $\gamma$ agonist pioglitazone inhibits microglia inflammation by blocking p38 mitogen-activated protein kinase signaling pathways," Inflammation Research, vol. 59, no. 11, pp. 921-929, 2010.

[24] B. Xing, T. Xin, R. L. Hunter, and G. Bing, "Pioglitazone inhibition of lipopolysaccharide-induced nitric oxide synthase is associated with altered activity of p38 MAP kinase and PI3K/ Akt," Journal of Neuroinflammation, vol. 5, article 4, 2008.

[25] E. Papageorgiou, N. Pitulis, P. Msaouel, P. Lembessis, and M. Koutsilieris, "The non-genomic crosstalk between PPAR$\gamma$ ligands and ERK1/2 in cancer cell lines," Expert Opinion on Therapeutic Targets, vol. 11, no. 8, pp. 1071-1085, 2007.

[26] R. E. Teresi, S. M. Planchon, K. A. Waite, and C. Eng, "Regulation of the PTEN promoter by statins and SREBP," Human Molecular Genetics, vol. 17, no. 7, pp. 919-928, 2008.

[27] W. K. Jung, I. S. Park, S. J. Park et al., “The 15-deoxy- $\Delta 12,14-$ prostaglandin J2 inhibits LPS-stimulated AKT and NF- $\kappa \mathrm{B}$ activation and suppresses interleukin-6 in osteoblast-like cells MC3T3E-1," Life Sciences, vol. 85, no. 1-2, pp. 46-53, 2009.

[28] E. S. Musiek, L. Gao, G. L. Milne et al., "Cyclopentenone isoprostanes inhibit the inflammatory response in macrophages," Journal of Biological Chemistry, vol. 280, no. 42, pp. $35562-$ 35570, 2005.

[29] M. Vinciguerra and M. Foti, "PTEN at the crossroad of metabolic diseases and cancer in the liver," Annals of Hepatology, vol. 7, no. 3, pp. 192-199, 2008.
[30] P. D. Ray, B. W. Huang, and Y. Tsuji, "Reactive oxygen species (ROS) homeostasis and redox regulation in cellular signaling," Cellular Signalling, vol. 24, no. 5, pp. 981-990, 2012.

[31] D. Trachootham, W. Lu, M. A. Ogasawara, N. Rivera-Del Valle, and P. Huang, "Redox regulation of cell survival," Antioxidants and Redox Signaling, vol. 10, no. 8, pp. 1343-1374, 2008.

[32] N. R. Leslie, D. Bennett, Y. E. Lindsay, H. Stewart, A. Gray, and C. P. Downes, "Redox regulation of PI 3-kinase signalling via inactivation of PTEN," The EMBO Journal, vol. 22, no. 20, pp. 5501-5510, 2003.

[33] A. de Luca, F. Sanna, M. Sallese et al., "Methionine sulfoxide reductase A down-regulation in human breast cancer cells results in a more aggressive phenotype," Proceedings of the National Academy of Sciences of the United States of America, vol. 107, no. 43, pp. 18628-18633, 2010.

[34] T. M. Covey, K. Edes, G. S. Coombs, D. M. Virshup, and F. A. Fitzpatrick, "Alkylation of the tumor suppressor PTEN activates Akt and $\beta$-catenin signaling: a mechanism linking inflammation and oxidative stress with cancer," PLoS ONE, vol. 5, no. 10, Article ID e13545, 2010.

[35] Y. Furumoto, S. Brooks, A. Olivera et al., "Cutting edge: lentiviral short hairpin RNA silencing of PTEN in human mast cells reveals constitutive signals that promote cytokine secretion and cell survival," Journal of Immunology, vol. 176, no. 9, pp. 5167-5171, 2006.

[36] Y. Anezaki, S. Ohshima, H. Ishii et al., "Sex difference in the liver of hepatocyte-specific Pten-deficient mice: a model of nonalcoholic steatohepatitis," Hepatology Research, vol. 39, no. 6, pp. 609-618, 2009.

[37] Y. Horie, A. Suzuki, E. Kataoka et al., "Hepatocyte-specific Pten deficiency results in steatohepatitis and hepatocellular carcinomas," Journal of Clinical Investigation, vol. 113, no. 12, pp. 1774-1783, 2004.

[38] P. Günzl, K. Bauer, E. Hainzl et al., "Anti-inflammatory properties of the PI3K pathway are mediated by IL-10/DUSP regulation," Journal of Leukocyte Biology, vol. 88, no. 6, pp. 1259-1269, 2010.

[39] J. C. Kim, Y. H. Lee, M. K. Yu et al., "Anti-inflammatory mechanism of PPAR $\gamma$ on LPS-induced pulp cells: role of the ROS removal activity," Archives of Oral Biology, vol. 57, no. 4, pp. 392-400, 2012.

[40] K. Hashimoto, B. J. Farrow, and B. M. Evers, "Activation and role of MAP kinases in 15d-PGJ ${ }_{2}$-induced apoptosis in the human pancreatic cancer cell line MIA PaCa-2," Pancreas, vol. 28, no. 2, pp. 153-159, 2004.

[41] Y. N. Jin, W. Y. Hwang, C. Jo, and G. V. Johnson, "Metabolic state determines sensitivity to cellular stress in Huntington disease: normalization by activation of PPAR $\gamma$," PLoS ONE, vol. 7, no. 1, Article ID e30406, 2012.

[42] J. Wang, X. Lv, J. Shi, X. Hu, and Y. Du, “Troglitazone induced apoptosis via PPAR $\gamma$ activated POX-induced ROS formation in HT29 cells," Biomedical and Environmental Sciences, vol. 24, no. 4, pp. 391-399, 2011.

[43] A. Martín, J. V. Pérez-Girón, R. Hernanz et al., "Peroxisome proliferator-activated receptor- $\gamma$ activation reduces cyclooxygenase- 2 expression in vascular smooth muscle cells from hypertensive rats by interfering with oxidative stress," Journal of Hypertension, vol. 30, no. 2, pp. 315-326, 2012.

[44] L. Q. Cao, X. L. Chen, Q. Wang et al., "Upregulation of PTEN involved in rosiglitazone-induced apoptosis in human hepatocellular carcinoma cells," Acta Pharmacologica Sinica, vol. 28 , no. 6 , pp. $879-887,2007$. 
[45] L. Q. Cao, X. L. Wang, Q. Wang et al., "Rosiglitazone sensitizes hepatocellular carcinoma cell lines to 5-fluorouracil antitumor activity through activation of the PPAR $\gamma$ signaling pathway," Acta Pharmacologica Sinica, vol. 30, no. 9, pp. 1316-1322, 2009.

[46] M. Schwab, V. Reynders, S. Loitsch et al., "PPAR $\gamma$ is involved in mesalazine-mediated induction of apoptosis and inhibition of cell growth in colon cancer cells," Carcinogenesis, vol. 29, no. 7, pp. 1407-1414, 2008.

[47] Y. Bren-Mattison, A. M. Meyer, V. van Putten et al., "Antitumorigenic effects of peroxisome proliferator-activated receptor$\gamma$ in non-small-cell lung cancer cells are mediated by suppression of cyclooxygenase- 2 via inhibition of nuclear factor- $\kappa \mathrm{B}$," Molecular Pharmacology, vol. 73, no. 3, pp. 709-717, 2008.

[48] S. Han and J. Roman, "Rosiglitazone suppresses human lung carcinoma cell growth through PPAR $\gamma$-dependent and PPAR $\gamma$ independent signal pathways," Molecular Cancer Therapeutics, vol. 5, no. 2, pp. 430-437, 2006.

[49] Y. Xiao, T. Yuan, W. Yao, and K. Liao, “3T3-L1 adipocyte apoptosis induced by thiazolidinediones is peroxisome proliferatoractivated receptor- $\gamma$-dependent and mediated by the caspase- 3 dependent apoptotic pathway," FEBS Journal, vol. 277, no. 3, pp. 687-696, 2010.

[50] R. E. Teresi, C. W. Shaiu, C. S. Chen, V. K. Chatterjee, K. A. Waite, and C. Eng, "Increased PTEN expression due to transcriptional activation of PPAR $\gamma$ by lovastatin and rosiglitazone," International Journal of Cancer, vol. 118, no. 10, pp. 2390-2398, 2006. 

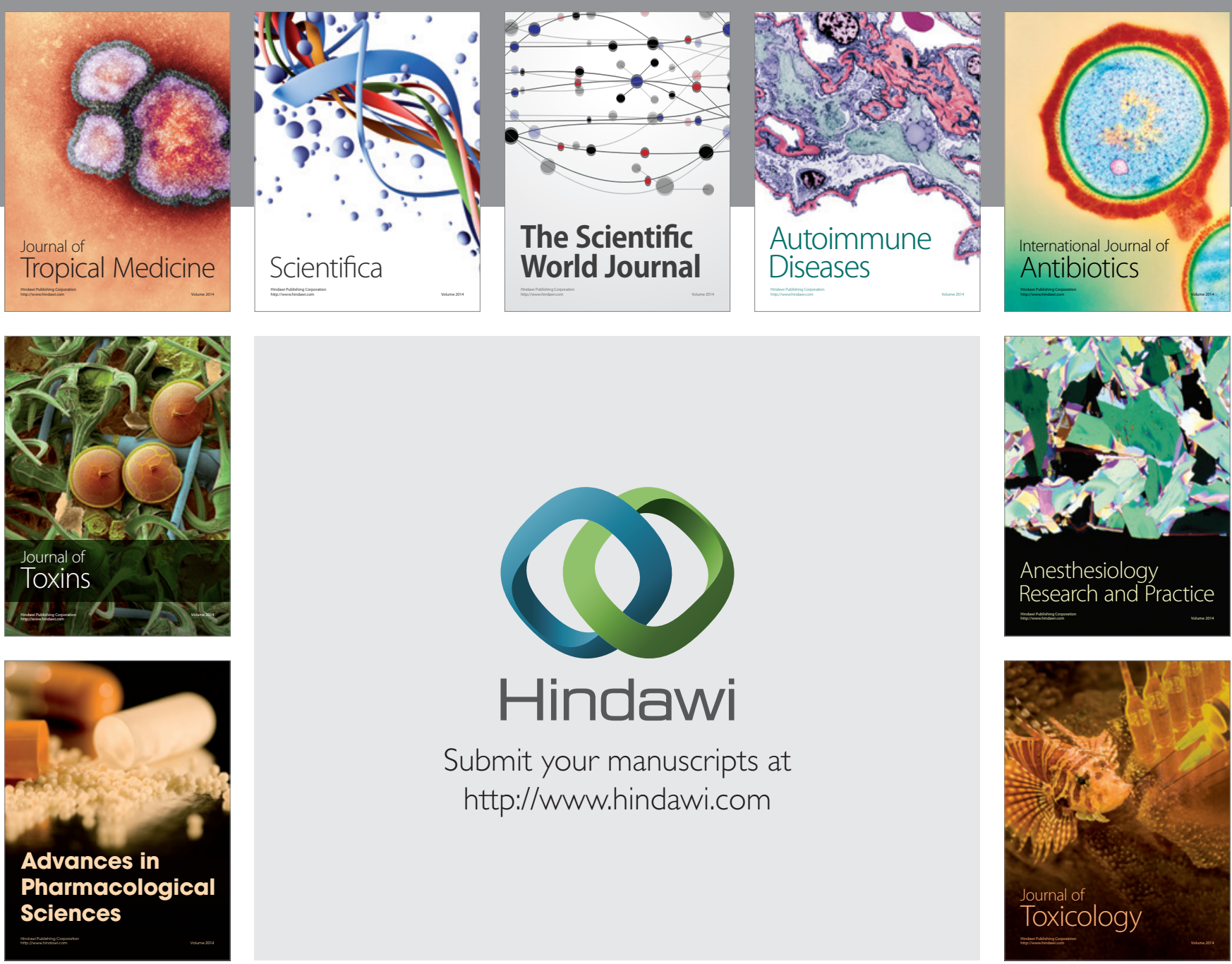

\section{Hindawi}

Submit your manuscripts at

http://www.hindawi.com
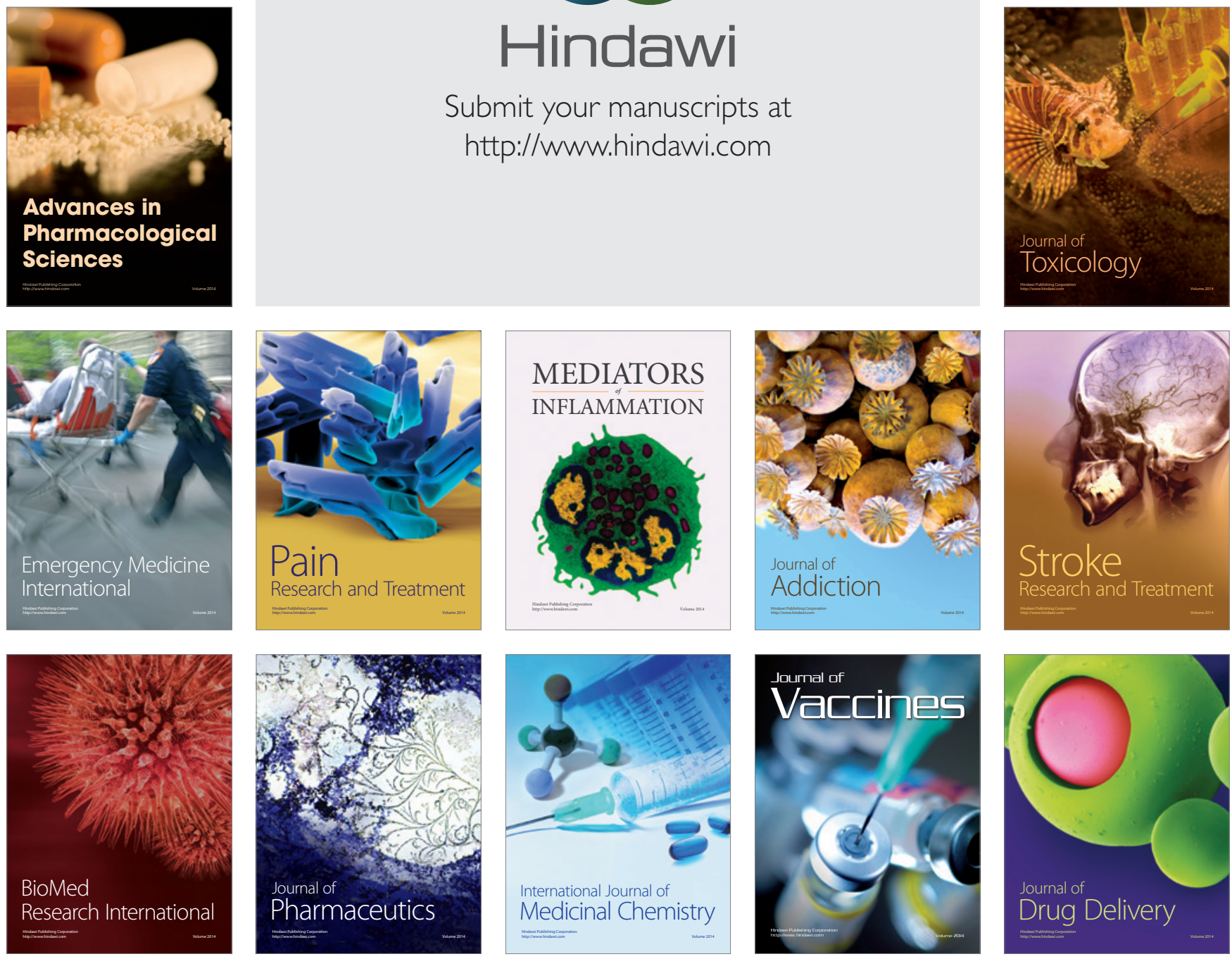